\title{
Determination of Multi-performance Characteristics in Electric Discharge Machining of DIN 1.2767 Steel Using Grey Relational Analysis
}

\author{
Abubaker Y. Fatatit ${ }^{1}$ and Ali Kalyon ${ }^{2}$ \\ ${ }^{1}$ Department of Manufacturing Engineering, Natural and Applied Sciences, Karabük University, \\ Karabük 078050, Turkey \\ ${ }^{2}$ Department of Mechanical Engineering, Faculty of Engineering, Yalova University, \\ Yalova 077200, Turkey
}

\begin{abstract}
Electric discharge machining (EDM) is one of the most important unconventional machining processes, which can cut hard materials and complex shapes that are difficult to machine by conventional machining processes easily and with high accuracy. In this study, L18 orthogonal array combined with gray relational analysis (GRA) is implemented to investigate the multiple performances characteristics in EDM of DIN 1.2767 Tool Steel. Machining process parameters selected were discharge current (Ip), pulse-on time $\left(\mathrm{T}_{\text {on }}\right)$, pulse-off time $\left(\mathrm{T}_{\text {off }}\right)$, and electrode material (copper alloys [NSS and B2]). The investigated performances characteristics were tool wear rate (TWR) and material removal rate (MRR). Analysis of variance (ANOVA) and Taguchi's signalto-noise ratio with the help of Minitab-17 software were used to analysis the effect of the process parameters on TWR and MRR. The experimental results and data analysis reveal that TWR and MRR are more affected by $I p$ and $T_{\text {on }}$. The minimum TWR was obtained at parametric combination Ip (6A), $T_{\text {on }}(800 \mu \mathrm{s})$, and $T_{\text {off }}$ $(800 \mu s)$ and the maximum MRR attained at Ip (25A), $T_{\text {on }}(800 \mu \mathrm{s})$, $\mathrm{T}_{\text {off }}(200 \mu \mathrm{s})$, and NSS electrode. After applying GRA, the optimal parametric combination for MRR and TWR was determined as Ip $(25 \mathrm{~A}), \mathrm{T}_{\text {on }}(800 \mu \mathrm{s}), \mathrm{T}_{\text {off }}(200 \mu \mathrm{s})$, and NSS electrode. The study also exhibited the occurrence of an interaction between the variables on the responses. In addition, scanning electron microscopy images showed that the metal surface was affected with the increase in $\mathbf{T}_{\text {on }}$ and $\mathbf{T}_{\text {off }}$
\end{abstract}

Index Terms-Electrical discharge machining, Gray relation, Optimization, Taguchi, DIN 1.2767 Tool steel.

\section{INTRODUCTION}

The greatly improved properties of new engineering materials made it difficult to machine using the conventional machining processes. Non-conventional

ARO-The Scientific Journal of Koya University

Vol. IX, No.1 (2021), Article ID: ARO.10718, 7 pages

DOI:10.14500/aro.10718

Received: 23 August 2020; Accepted: 16 January 2021

Regular research paper: Published 01 March 2021

Corresponding author's e-mail: ali.kalyon@yalova.edu.tr

Copyright (C 2021 Abubaker Y. Fatatit and Ali Kalyon. This is an open-access article distributed under the Creative Commons Attribution License. machining processes can easily machine hard and brittle materials, complex geometries, and delicate components with tight tolerance, extreme surface finish, and free of burrs. Electric discharge machining (EDM) is one of the non-conventional machining processes that based on the conversion of electric energy into extremely high temperature (plasma channel) in localized region impinge on the work material surface caused melting or evaporating (Amorim and Weingaertner, 2007; Ho and Newman, 2003; Muthuramalingam and Mohan, 2015). The width and intensity of the plasma channel depend on many parameters which have complex relationships between each other in addition to other factors that affect the process's mechanism, making it difficult to achieve optimal performance for the EDM process. High temperature causes melt and wear of the electrode. The most used electrodes, with high conductivity of electricity and a high melting point such as copper, are tungsten, copper tungsten, silver tungsten aluminum, graphite and other, and metals and alloys. The selection of electrode material relies on the type of the EDM machine power supply circuit, the surface quality, and the type of workpiece material that is to be machined (Daniel, 2019; Shyha and Rudd, 2016).

Several experimental tests, which have been conducted to increase efficiency and improve EDM process performance, were related to EDM and mentioned that substantial researches have been conducted for improving EDM performance measures such as material removal rate (MRR), tool wear rate (TWR), surface roughness (Ra), and wear ratio. The most widely used material are steel materials, EN series, Ti-6AL-4V, SiC, $\mathrm{B}_{4} \mathrm{C}, \mathrm{WC}-\mathrm{Co}, \mathrm{Al}_{2} \mathrm{O}_{3}+\mathrm{Ti} \mathrm{S} 45 \mathrm{C}$, and Inconel 718. The main electric input parameters have been used are $\mathrm{T}_{\text {on }}, \mathrm{T}_{\text {off }}, \mathrm{Ip}$, and $\mathrm{V}$ and non-electric parameters including dielectric medium, flashing pressure, and electrode rotation. There are many optimization techniques and result analysis tools used such as Taguchi, response surface methodology, gray relationships analysis, ANOVA, and multiple regression analysis (Ramabalan and S, 2015; Patil and Jadhav, 2016).

Yerui et al., 2016, conducted experiments on TiC/Ni using EDM. The experimental results revealed that as the Ip 
increased, the discharge energy increased, which results in an increase in the MRR. MRR increases with the increase of $\mathrm{T}_{\text {on }}$, but when $\mathrm{T}_{\text {on }}$ was longer than $30 \mu \mathrm{s}$ MRR decreased slowly. This was as a result of the expansion of the plasma channel and the effect of debris on it. Dastagiri and Kumar, 2014, reported that the higher the Ip, the more discharging energy. Then, the metal temperature rises in a very localized region, thus more MRR can be achieved. $T_{\text {on }}$ increases, MRR increases and then decreases. Kalyon, 2020, applied Taguchi method and gray relational analysis (GRA) for optimization of EDM of Caldie cold work tool steel, considering process parameters such as Ip, $\mathrm{T}_{\text {on }}$, and electrode materials (graphite and copper). The results revealed that with increasing Ip and $\mathrm{T}_{\text {on }}$, the MRR and $\mathrm{Ra}$ increased. The optimal parameter setting for maximum MRR and minimum $\mathrm{Ra}$ obtained by GRA is graphite electrode, $6 \mathrm{~A}$ and $50 \mu \mathrm{s}$. Habib, 2009, performed experiments using copper as a tool electrode on an EDM with selected input parameters on conductive metal matrix composite $\mathrm{Al} / \mathrm{SiC}$. Results of the study showed that the higher Ip offered higher MRR. An increase of Ton caused an increase in MRR until it reached $200 \mu$ s and then MRR began to decrease. TWR was found to be directly proportional to Ip and Ton. Gopalakannan et al., 2013, investigated EDM performance and optimizing the process parameters of AL7075-B $\mathrm{C}_{4} \mathrm{MMC}$ using response surface methodology. The process parameters were Ip, $\mathrm{T}_{\text {on }}, \mathrm{T}_{\text {off }}$, and gap voltage. It was concluded that the two main significant process parameters that affect the MRR were Ip and $T_{\text {on }}$. The MRR increased with the increase in $T_{\text {on }}$ and then decreased with longer $T_{\text {on }}$. Furthermore, TWR decreased with the increase of $\mathrm{T}_{\text {on }}$. Ip and $\mathrm{T}_{\text {on }}$ have statistically significant effect on TWR. Venkatesh et al., 2015, studied the EDM performance of EN 31, EN 8, and $\mathrm{HCHCr}$, and they used three electrodes, copper, brass, and chromium copper. They mentioned that the optimal MRR and TWR were at chromium copper electrode followed by copper then brass. The brass electrode achieved minimal surface roughness, but TWR was high and MRR was low. Besides, performance measures were influenced by workpiece material. Kumar, 2012, conducted EDM experiments on OHNS Die Steel using three different electrodes (copperchromium, brass, and copper). Their results showed that the copper-chromium electrode produced higher MRR, better surface finish, and lower TWR compared to other electrodes. Lin and Lin, 2002, adopted the orthogonal array (OA) with GRA for multiperformance characteristics optimization of KD11 alloy steel. It was concluded that the performance characteristics such as MRR, TWR, and surface roughness were improved. Doniavi et al., 2008; Singh et al., 2004, concluded that OA and GRA can be successfully applied to obtain optimal level of EDM process parameters for multiperformance characteristics.

The electrode performance used in EDM is an important problem affecting machinability. TWR and MRR are important performance measures when evaluating the electrode performance. The low rate of wear of the electrode will ensure the dimensional integrity of the workpiece. High MRR will result in shorter machining times and reduced machining costs. This study aims to determine the optimal parametric setting for minimizing TWR and maximizing MRR on DIN 1.2767 steels by applying GRA. In addition to determine the effect of the process parameters on TWR and MRR Taguchi optimization method was used. As a result, machinability of DIN 2767 Tool Steel was improved by using application of EDM method.

\section{EXPERIMENTAL SETUP}

The experiments were designed according to $\mathrm{L}_{18}$ Taguchi $\mathrm{OA}$ and performed on the FURKAN M25A sinker EDM machine. The experimental setup of EDM machine is shown in Fig. 1. Two electrodes, B2 and NSS, with a diameter of $16 \mathrm{~mm}$ were used. The physical properties and chemical compositions of electrodes are presented in Tables I-III. Before conducting each experiment, the electrode was polished on silicon carbide paper with grit sizes in this sequence, 150, 240, 320, 400, 600, and 800. The work material was DIN 1.2767 tool steel. This type of steel has crucial application in industry such as cutting and bending tools, drawing jaws, plastic molds, gears requiring shock resistance, heavy-duty shafts, and axles. Its chemical composition is listed in Table IV.

The size of each workpiece is $50 \mathrm{~mm} \times 25 \mathrm{~mm} \times 12 \mathrm{~mm}$. The work materials' surface was machined by milling and grinding machines before conducting the EDM experiments. The electrode materials, Ip, $\mathrm{T}_{\text {on }}$, and $\mathrm{T}_{\text {off }}$, were selected as process parameters. Table $\mathrm{V}$ illustrates the process parameters and their levels. The polarity of the workpieces was positive and the electrode was negative. The kerosene was chosen as a dielectric fluid with lateral flushing pressure of 0.25 bar. The EDM time of each experiment was $1 \mathrm{~h}$. The workpieces and the electrode were weighed before and after conducting the experiments. MRR and TWR can be calculated as below:

$$
\operatorname{MRR}\left(\mathrm{mm}^{3} / \min \right)=\frac{W_{i}-W_{f}}{t^{*} \rho}
$$

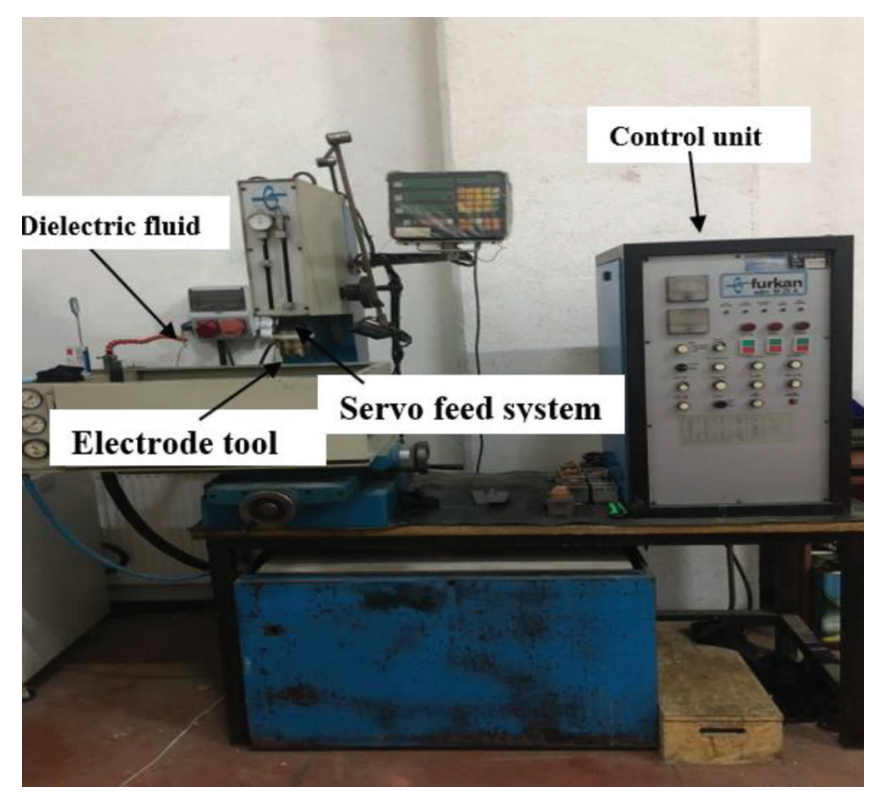

Fig. 1. Electric discharge machining (FURKAN M25A). 
TABLE I

PhySiCAL PROPERTIES OF THE ELECTRODES

\begin{tabular}{lcccc}
\hline \hline Material & $\begin{array}{c}\text { Density } \\
\left(\mathrm{g} / \mathrm{cm}^{3}\right)\end{array}$ & $\begin{array}{c}\text { Electrical } \\
\text { conductivity } \\
(\mathrm{MS} / \mathrm{m})\end{array}$ & $\begin{array}{c}\text { Thermal } \\
\text { conductivity } \\
(\mathrm{W} / \mathrm{m} \mathrm{K})\end{array}$ & $\begin{array}{c}\text { Melting } \\
\text { temperature } \\
\text { range }\left({ }^{\circ} \mathrm{C}\right)\end{array}$ \\
\hline $\mathrm{B} 2$ & 8,3 & $\geq 16$ & $120-170$ & $870-980$ \\
$\mathrm{NSS}$ & 8,81 & $\geq 23$ & $190-240$ & $1020-1040$ \\
\hline \hline
\end{tabular}

TABLE II

Chemical COMPosition of NsS (CUNi2SiCR)

\begin{tabular}{lccccccl}
\hline \hline Element & $\mathrm{Si}$ & $\mathrm{Mn}$ & $\mathrm{Cr}$ & $\mathrm{Ni}$ & $\mathrm{Fe}$ & $\mathrm{Pb}$ & $\mathrm{Cu}$ \\
\hline Weight $(\%)$ & 0,65 & 0,10 & 0,35 & 2,5 & 0,15 & 0,02 & Balance \\
\hline \hline
\end{tabular}

TABLE III

Chemical composition of B2 (CuBe2)

\begin{tabular}{lccccl}
\hline \hline Element & $\mathrm{Ni}$ & $\mathrm{Be}$ & $\mathrm{Co}$ & $\mathrm{Fe}$ & $\mathrm{Cu}$ \\
\hline Weight $(\%)$ & 0,30 & 1,95 & 0,30 & 0,20 & Balance \\
\hline \hline
\end{tabular}

TABLE IV

Chemical COMPosition OF DIN 1.2767

\begin{tabular}{lccccccl}
\hline \hline Element & $\mathrm{C}$ & $\mathrm{Si}$ & $\mathrm{Mn}$ & $\mathrm{Cr}$ & $\mathrm{Mo}$ & $\mathrm{Ni}$ & $\mathrm{Fe}$ \\
\hline Weight $(\%)$ & 0,45 & 0,25 & 0,35 & 1,35 & 0,25 & 4,05 & Balance \\
\hline \hline
\end{tabular}

TABLE V

CONTROL FACTORS AND LEVELS

\begin{tabular}{llcccc}
\hline \hline Factor notation & Factor & Unit & Level 1 & Level 2 & Level 3 \\
\hline E & Tool material & & NSS & B2 & \\
A & Ip & A & 6 & 12 & 25 \\
B & Ton & $\mu s$ & 50 & 200 & 800 \\
C & Toff & $\mu s$ & 50 & 200 & 800 \\
\hline \hline
\end{tabular}

$$
\operatorname{TWR}\left(\mathrm{mm}^{3} / \mathrm{min}\right)=\frac{T_{i}-T_{f}}{t^{*} \rho}
$$

Where, $W_{i}$ is the initial weight of the workpiece, $W_{f}$ is the final weight, $T_{i}$ is the initial weight of the electrode, $T_{f}$ is the final weight of the electrode, $\rho$ is the density, and $t$ is the machining time in minutes.

Table VI shows the values of TWR and MRR after performing experiments according to $\mathrm{L}_{18}$ Taguchi $\mathrm{OA}$ and performing the calculations of MRR and TWR by applying Equations 1 and 2.

\section{TAGUCHI's SIGNAL-TO-NOISE RATIO (S/N)}

Taguchi's $\mathrm{S} / \mathrm{N}$ is a statistic that combines the mean and variance. The goal of robust experimentation is to determine an optimal combination of process parameters (control factor) settings that achieve robustness against factors that cause variability in the performance (noise factors). Selecting type of $\mathrm{S} / \mathrm{N}$ depending on the goal of the experiments. In the case of the "smaller the better," $\mathrm{S} / \mathrm{N}$ is calculated according to Equation 3, which is used when calculating TWR. When calculating MRR, larger the better, and the $\mathrm{S} / \mathrm{N}$ ratio is given by Equation 4. Higher values of the $\mathrm{S} / \mathrm{N}$ indicate process parameter settings that optimize the performance characteristics (Krishnaiah and Shahabudeen, 2012).

$$
\begin{aligned}
& S / N=-10 \log \left[\frac{1}{n} \sum_{i=1}^{n} y_{i}^{2}\right] \\
& S / N=-10 \log \left[\frac{1}{n} \sum_{i=1}^{n} \frac{1}{y_{i}^{2}}\right]
\end{aligned}
$$

Where, $y_{i}$ is the performance response, $i$ is the observation value, and $n$ is the number of tests in an experiment.

\section{GRA}

In many experiments and studies, process parameters cannot be set only for one response. Because of many reasons, one of them is that the objective is to maximize some responses and to minimize some responses together. GRA is among methods that can be employed to solve/optimize multiresponse problems. In GRA, the multiresponses are converted into a single response and then attain the levels of the optimal factors (Kalyon et al., 2018; Singh, 2018). Optimization in GRA is performed as the following steps:

1. Data pre-processing: Translation of responses values $Y_{i j}$ into normalized values $Z_{i j}\left(0 \leq Z_{i j} \leq 1\right)$. In case of normalized data processing for the response larger the better, Equation (5) is used, if the response smaller the better, the Equation (6) is applied and if the response is nominal the best, then the normalized values can be expressed by Equation (7).

$$
\begin{aligned}
Z_{i j} & =\frac{Y_{i j}-\min \left(Y_{i j}, i=1,2 \ldots, n\right)}{\max \left(Y_{i j}, \quad i=1,2 \ldots ., n\right)-\min \left(Y_{i j}, i=1,2 \ldots ., n\right)} \\
Z_{i j} & =\frac{\max \left(Y_{i j}, i=1,2 \ldots, n\right)-Y_{i j}}{\max \left(Y_{i j}, \quad i=1,2 \ldots, n\right)-\min \left(Y_{i j}, i=1,2 \ldots ., n\right)}
\end{aligned}
$$

$$
Z_{i j}=\frac{\left(\left|Y_{i j}-T\right|\right)-\min \left(\left|Y_{i j}-T\right|, i=1,2 \ldots, n\right)}{\max \left(\left|Y_{i j}-T\right|, i=1,2 \ldots ., n\right)-\min \left(\left|Y_{i j}-T\right|, i=1,2 \ldots, n\right)}
$$

where: $\mathrm{i}=1,2 \ldots, \mathrm{n}$ experiments. $Y_{i j}=$ the $\mathrm{i}^{\text {th }}$ normalized value of the $\mathrm{j}^{\text {th }}$ response variable.

2. Gray relational coefficient: Gray relational coefficient is implemented for obtaining how close ideal and normalized response $\mathrm{Zij}$ are. The gray relational coefficient can be expressed by Equation (8).

$$
G C_{i j}=\frac{\Delta_{\min }+\lambda \Delta_{\max }}{\Delta_{i j}+\lambda \Delta_{\max }}
$$

where: $\Delta=\left|Y_{o j}-Y_{i j}\right|, \Delta_{\text {min }}=$ minimum value of $\Delta$, $\Delta_{\max }=$ maximum value of $\Delta, Y_{o j}=$ the ideal normalized value of th response, $\lambda=$ distinguish coefficient in between zero and one. It dominates the range of the gray relational coefficient.

3. Gray relational grade $\left(G_{j}\right)$ : The $G_{j}$ computes the average sum of the $G C_{i j}$, and it is calculated as in Equation (9). The highest value of $G_{j}$ is referred to optimal multiple response. Where $m$ is number of responses. 
TABLE VI

EXPERIMENTAL RESULTS

\begin{tabular}{|c|c|c|c|c|c|c|c|}
\hline Exp. No. & Control factors & Tool & $\operatorname{Ip}(\mathrm{A})$ & Ton $(\mu s)$ & Toff $(\mu s)$ & Tool wear rate $\left(\mathrm{mm}^{3} / \mathrm{min}\right)$ & Material removal rate $\left(\mathrm{mm}^{3} / \mathrm{min}\right)$ \\
\hline 1 & $\mathrm{E}_{1} \mathrm{~A}_{1} \mathrm{~B}_{1} \mathrm{C}_{1}$ & NSS & 6 & 50 & 50 & 0,25 & 3,59 \\
\hline 2 & $\mathrm{E}_{1} \mathrm{~A}_{1} \mathrm{~B}_{2} \mathrm{C}_{2}$ & NSS & 6 & 200 & 200 & 0,19 & 2,16 \\
\hline 3 & $\mathrm{E}_{1} \mathrm{~A}_{1} \mathrm{~B}_{3} \mathrm{C}_{3}$ & NSS & 6 & 800 & 800 & 0,02 & 0,06 \\
\hline 4 & $\mathrm{E}_{1} \mathrm{~A}_{2} \mathrm{~B}_{1} \mathrm{C}_{2}$ & NSS & 12 & 50 & 200 & 1,63 & 4,65 \\
\hline 5 & $\mathrm{E}_{1} \mathrm{~A}_{2} \mathrm{~B}_{2} \mathrm{C}_{3}$ & NSS & 12 & 200 & 800 & 0,19 & 7,2 \\
\hline 6 & $\mathrm{E}_{1} \mathrm{~A}_{2} \mathrm{~B}_{3} \mathrm{C}_{1}^{3}$ & NSS & 12 & 800 & 50 & 0,02 & 4,01 \\
\hline 7 & $\mathrm{E}_{1} \mathrm{~A}_{3} \mathrm{~B}_{1} \mathrm{C}_{3}$ & NSS & 25 & 50 & 800 & 1,68 & 2,86 \\
\hline 8 & $\mathrm{E}_{1} \mathrm{~A}_{3} \mathrm{~B}_{2} \mathrm{C}_{1}$ & NSS & 25 & 200 & 50 & 2,19 & 22,72 \\
\hline 9 & $\mathrm{E}_{1} \mathrm{~A}_{3} \mathrm{~B}_{3} \mathrm{C}_{2}$ & NSS & 25 & 800 & 200 & 0,15 & 25,24 \\
\hline 10 & $\mathrm{E}_{2} \mathrm{~A}_{1} \mathrm{~B}_{1} \mathrm{C}_{1}$ & B2 & 6 & 50 & 50 & 0,63 & 2,01 \\
\hline 11 & $\mathrm{E}_{2} \mathrm{~A}_{1} \mathrm{~B}_{2} \mathrm{C}_{2}$ & B2 & 6 & 200 & 200 & 0,02 & 1,97 \\
\hline 12 & $\mathrm{E}_{2} \mathrm{~A}_{1} \mathrm{~B}_{3} \mathrm{C}_{3}$ & B2 & 6 & 800 & 800 & 0,02 & 0,65 \\
\hline 13 & $\mathrm{E}_{2} \mathrm{~A}_{2} \mathrm{~B}_{1} \mathrm{C}_{2}$ & B2 & 12 & 50 & 200 & 0,66 & 0,8 \\
\hline 14 & $\mathrm{E}_{2} \mathrm{~A}_{2} \mathrm{~B}_{2} \mathrm{C}_{3}$ & $\mathrm{~B} 2$ & 12 & 200 & 800 & 0,4 & 4,08 \\
\hline 15 & $\mathrm{E}_{2} \mathrm{~A}_{2} \mathrm{~B}_{3} \mathrm{C}_{1}$ & B2 & 12 & 800 & 50 & 0,04 & 4,35 \\
\hline 16 & $\mathrm{E}_{2} \mathrm{~A}_{3} \mathrm{~B}_{1} \mathrm{C}_{3}$ & B2 & 25 & 50 & 800 & 1,14 & 0,65 \\
\hline 17 & $\mathrm{E}_{2} \mathrm{~A}_{3} \mathrm{~B}_{2} \mathrm{C}_{1}$ & B2 & 25 & 200 & 50 & 2,42 & 18,14 \\
\hline 18 & $\mathrm{E}_{2} \mathrm{~A}_{3} \mathrm{~B}_{3} \mathrm{C}_{2}$ & $\mathrm{~B} 2$ & 25 & 800 & 200 & 0,36 & 20,5 \\
\hline
\end{tabular}

$$
G_{j}=\frac{1}{m} \sum G C_{i j}
$$

Where: $m$ is number of responses.

\section{RESUlTS AND Discussion}

\section{A. Effect of the Process Parameters on TWR and MRR}

Taguchi's $\mathrm{S} / \mathrm{N}$ is used in the analysis of experiments results to indicate the effect of the process parameters and the process parameter settings that optimize the performance characteristics. Fig. 2 shows the main effects plot for $\mathrm{S} / \mathrm{N}$ of MRR and TWR, where smaller is better is used in the case of TWR and larger is better in the case of MRR. It is clear that the optimum value of MRR gained by NSS electrode, Ip (25A), $\mathrm{T}_{\text {on }} 200 \mu \mathrm{s}$, and $\mathrm{T}_{\text {off }} 50 \mu \mathrm{s}$ and optimum value of TWR gained at parameters Ip $6 \mathrm{~A}, \mathrm{~T}_{\text {on }} 800 \mu \mathrm{s}$, and $\mathrm{T}_{\text {off }} 800$ $\mu$ s while the effect of both electrodes on TWR response is close. MRR is directly proportional to Ip and inversely proportional to $\mathrm{T}_{\text {off }}$. Similar observation has been reported by Lee and $\mathrm{Li}, 2001$. As Ip increases, discharge energy increases, the highest temperature reached on the workpiece is also increases, hence, more MRR achieved (Dastagiri and Kumar, 2014). Furthermore, as it shown, MRR is directly proportional to Ip and inversely proportional to $T_{\text {off }}$ The increase of the $T_{o n}$, TWR decreases gradually while MRR increases. However, a long $\mathrm{T}_{\text {on }}$, MRR decreased. This decrease is due to the expansion of the electric plasma channel (Dastagiri and Kumar, 2014; Kalyon, 2020; Kumar, 2012). On the other hand, Lee and Li (2001) explained that a long Ton causes the arcing and decreases MRR. Furthermore, as it is shown, the NSS electrode achieves the best MRR while the effect of both electrodes on TWR response is close.

Interaction exists when the influence of one process parameters depends on the level of the other process

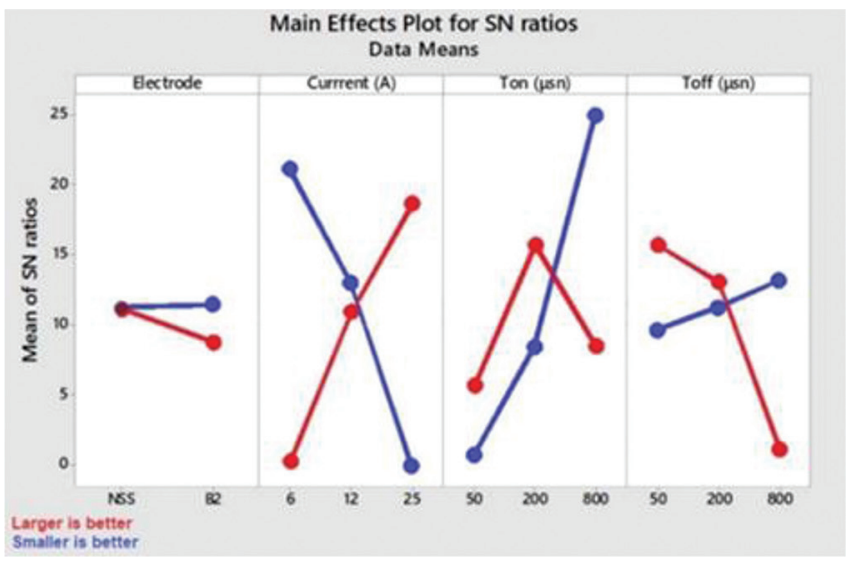

Fig. 2. Signal-to-noise ratio for tool wear rate and material removal rate.

parameter (Antony, 2003). Fig. 3-5 represent the combined effect (interaction) of process parameters on TWR. It is clear that the change in TWR from level to level of any process parameter depends on the level of the other parameter. While, the fluctuating effect of these parameters on the TWR was observed, but a lower TWR could be achieved when treated with the parameters Ip $(6 \mathrm{~A})$, Ton $(800 \mu \mathrm{s})$, and Toff $(800 \mu \mathrm{s})$. Hence, minimum TWR can be achieved at low Ip and high values of Ton and Toff.

The interaction effects of parameters for MRR are illustrated in Fig. 6-8. It is seen the strong combined effect of process parameters on MRR. As can be seen from figure, MRR is positively affected by increase of Ip. For achieving maximum MRR, the optimum process parameter settings are $\mathrm{Ip}=25 \mathrm{~A}, \mathrm{~T}_{\text {on }}=800 \mu \mathrm{s}$ and $\mathrm{T}_{\text {off }}=200 \mu \mathrm{s}$ or $\mathrm{Ip}=25 \mathrm{~A}$, $\mathrm{T}_{\text {on }}=200 \mu \mathrm{s}$ and $\mathrm{T}_{\text {off }}=50 \mu \mathrm{s}$.

It is important to study the contribution of the process parameters because not all parameters affect the performance in the same manner. Fig. 9 shows the results of the ANOVA analysis in determining the contribution of process parameters to TWR and MRR. Ip has the most significant effect on the 


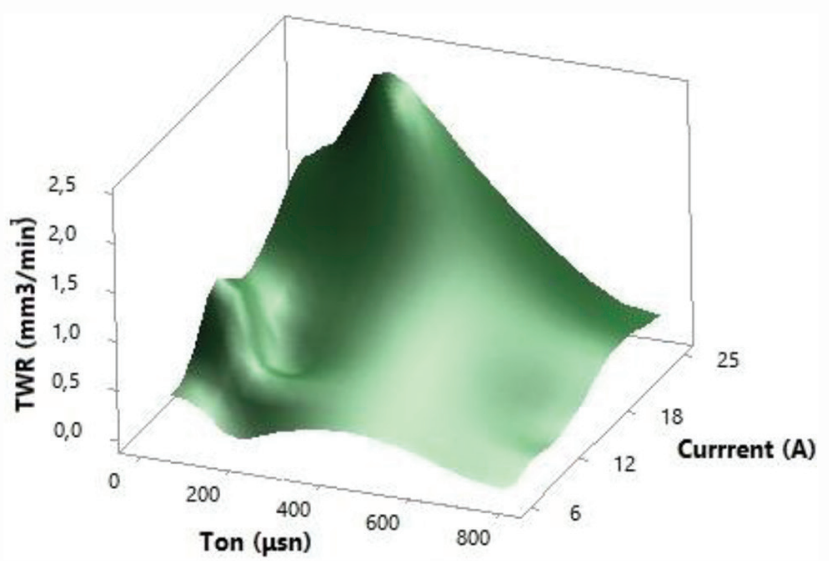

Fig. 3. Effect of $\mathrm{T}_{\text {on }}$ and current on tool wear rate.

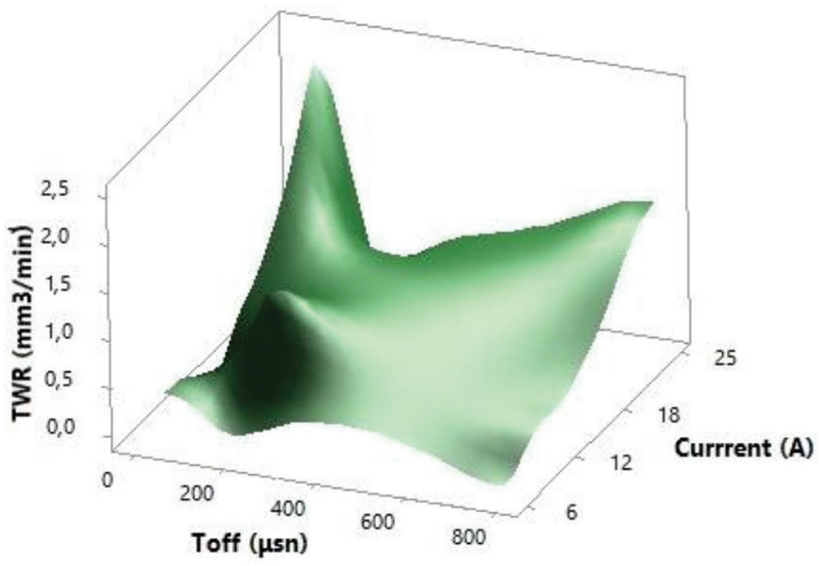

Fig. 4. Effect of $\mathrm{T}_{\text {off }}$ and current on tool wear rate.

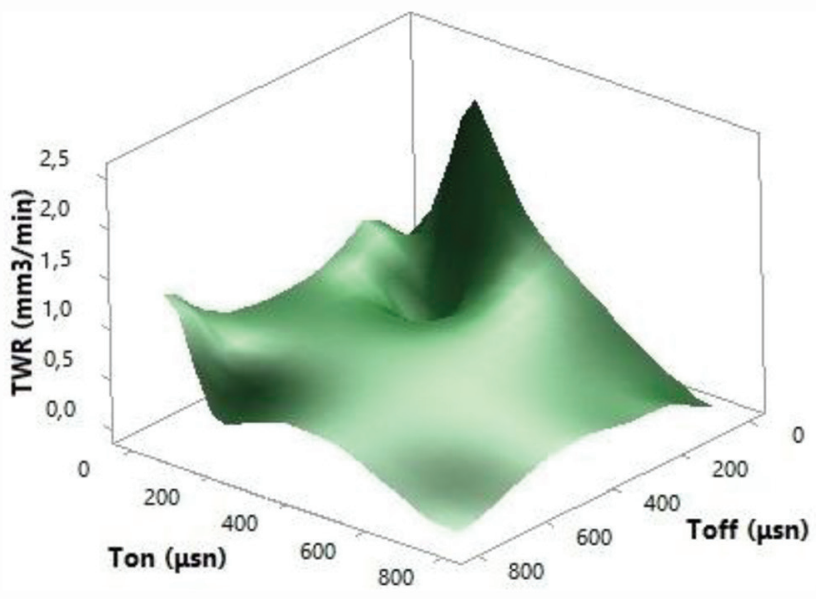

Fig. 5. Effect of $\mathrm{T}_{\text {on }}$ and $\mathrm{T}_{\text {off }}$ on tool wear rate.

MRR and EWR followed by $T_{\text {on }}$ and $T_{\text {off }}$ while electrode material has the least effect on MRR and TWR. By focusing on the most influencing factors, a higher performance improvement ratio can be obtained. It is also clear that Ip and $\mathrm{T}_{\text {off }}$ have higher impact ratios in the case of MRR compared to the TWR. In the case of $T_{\text {on }}$, the rate of impact on the TWR is higher. In Ton, the TWR effect is higher. Electrode material has a negligible effect for both responses.

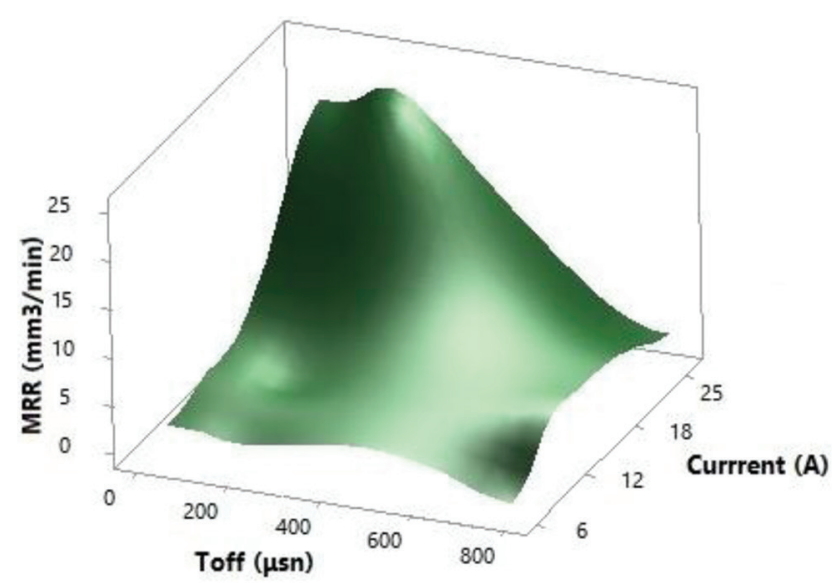

Fig. 6. Effect of $\mathrm{T}_{\text {off }}$ and current on material removal rate.

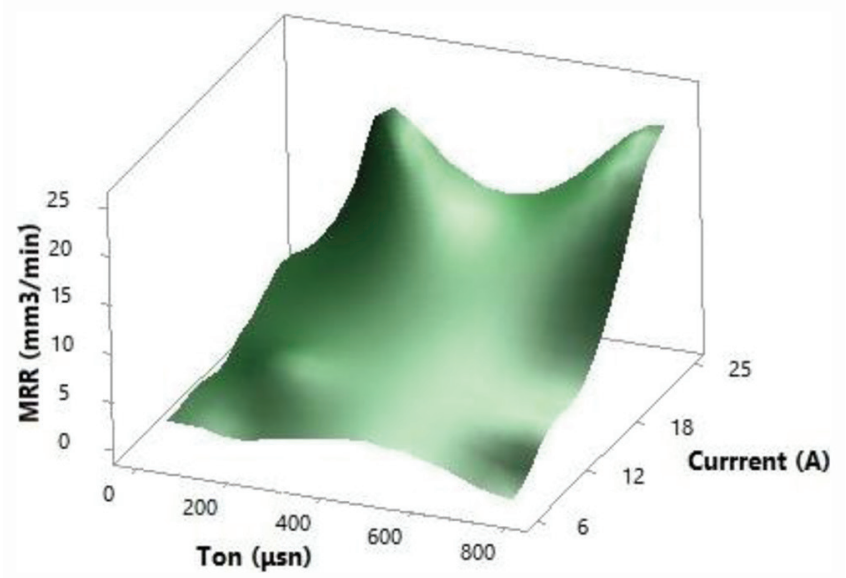

Fig. 7. Effect of $\mathrm{T}_{\text {on }}$ and current on material removal rate.

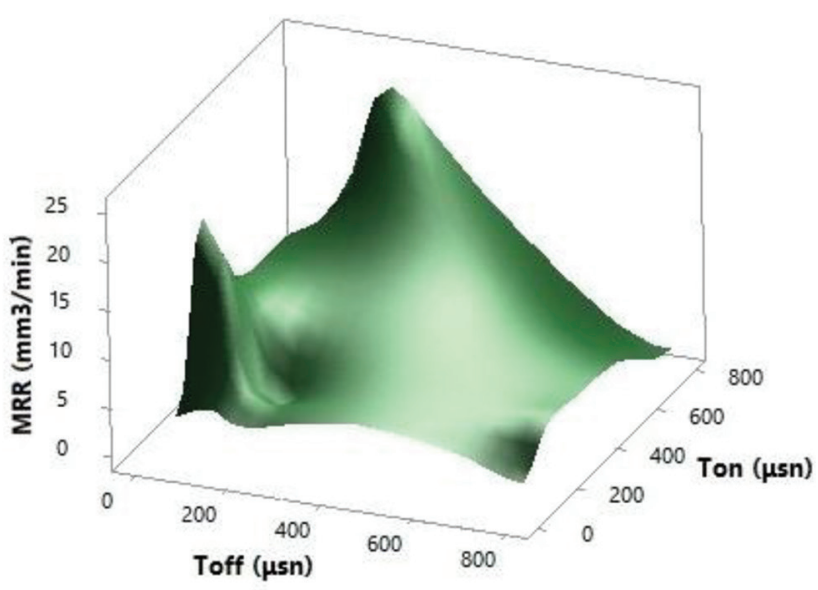

Fig. 8. Effect of $\mathrm{T}_{\text {off }}$ and $\mathrm{T}_{\text {on }}$ on material removal rate.

\section{B. Multiresponse Optimization with GRA}

From Fig. 2, we note that the values of the process parameters that achieve optimal MRR differ from the values of the process parameters that achieve optimal TWR. While, the study aims to obtain the optimal set of process parameters to achieve the minimum TWR and maximum MRR. To achieve this, GRA provides statistical and mathematical 
equations which enables it to optimize multiobjective problems (Harpreet and Amandeep, 2012; Krishnaiah and Shahabudeen, 2012; Singh, 2018). After implementing the GRA steps as in Equations 5-9 which were previously mentioned, the results are shown in Table VII. It is clear from the last column in the table that Experiment 9 was

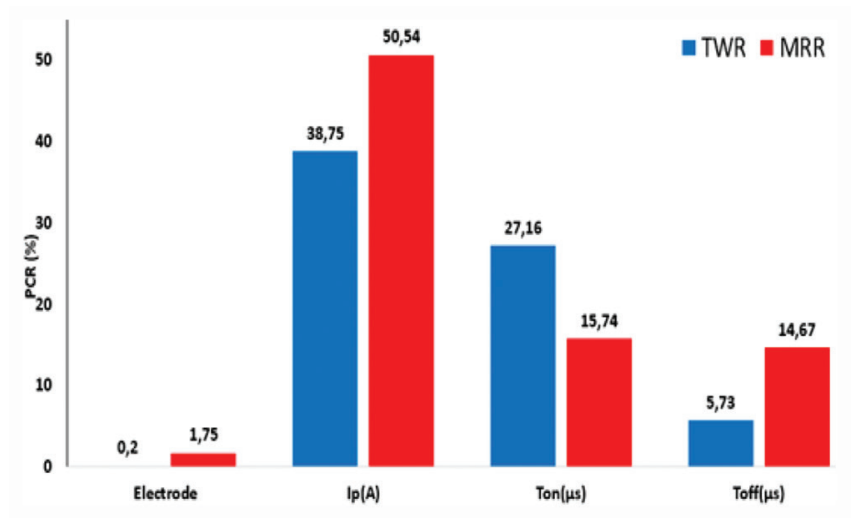

Fig. 9. Effect of parameters on tool wear rate and material removal rate as a result of ANOVA.
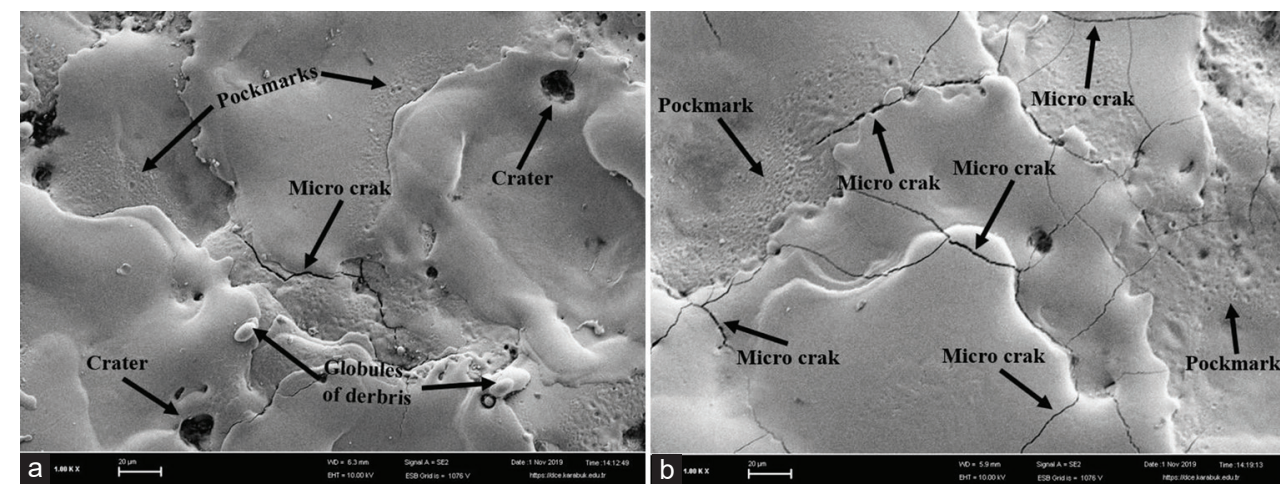

Fig. 10. Scanning electron microscopy surface images: (a) Process parameters Ip (6 A), $\mathrm{T}_{\text {on }}(50 \mu \mathrm{s})$, and $\mathrm{T}_{\text {off }}(50 \mu \mathrm{s})$, (b) process parameters Ip (6 A), $\mathrm{T}_{\text {on }}$ $(200 \mu \mathrm{s})$, and $\mathrm{T}_{\text {off }}(200 \mu \mathrm{s})$.

TABLE VII

NORMALIZATION AND COEFFICIENT MATRIX VALUES

\begin{tabular}{|c|c|c|c|c|c|c|}
\hline $\begin{array}{l}\text { Exp. } \\
\text { No. }\end{array}$ & $\begin{array}{l}\text { Normalized tool } \\
\text { wear rate }\end{array}$ & $\begin{array}{l}\text { Normalized material } \\
\text { removal rate }\end{array}$ & $\begin{array}{l}\text { Gray relation coefficient } \\
\text { tool wear rate }\end{array}$ & $\begin{array}{l}\text { Gray relation coefficient } \\
\text { material removal rate }\end{array}$ & $\begin{array}{l}\text { Gray relation } \\
\text { grade }\end{array}$ & Rank \\
\hline 1 & 0,904 & 0,140 & 0,839 & 0,368 & 0,603 & 10 \\
\hline 2 & 0,929 & 0,083 & 0,876 & 0,353 & 0,614 & 9 \\
\hline 4 & 0,329 & 0,182 & 0,427 & 0,379 & 0,403 & 17 \\
\hline 5 & 0,929 & 0,284 & 0,876 & 0,411 & 0,643 & 8 \\
\hline 6 & 1,000 & 0,157 & 1,000 & 0,372 & 0,686 & 3 \\
\hline 9 & 0,946 & 1,000 & 0,902 & 1,000 & 0,951 & 1 \\
\hline 10 & 0,746 & 0,077 & 0,663 & 0,351 & 0,507 & 13 \\
\hline 11 & 1,000 & 0,076 & 1,000 & 0,351 & 0,676 & 5 \\
\hline 12 & 1,000 & 0,023 & 1,000 & 0,339 & 0,669 & 6 \\
\hline 13 & 0,733 & 0,029 & 0,652 & 0,340 & 0,496 & 14 \\
\hline 18 & 0,858 & 0,812 & 0,779 & 0,726 & 0,753 & 2 \\
\hline
\end{tabular}


The values of SCD reported by Bhattacharyya et al., 2007, were minimum at Ip and $\mathrm{T}_{\text {on }}$ in range 18-22 $\mathrm{A}$ and $20-100$ $\mu \mathrm{s}$, respectively. Guu, 2005, concluded that low discharge energy should be used to avoid surface damage.

\section{CONCLUSIONS}

This paper presented the use of OA with GRA for the optimization for the EDM process with the multiple performance characteristics. Taguchi method and ANOVA were applied to determine the contribution of parameters which affecting MRR and TWR. The main conclusions of this paper are summarized as follows:

- Ip was the most significant process parameter followed by $\mathrm{T}_{\text {on }}, \mathrm{T}_{\text {off }}$, and electrode material, respectively

- When Ip increased, MRR increases gradually. With the increase of $T_{\text {on }}$, MRR increased first and then decreases. MRR decreases with increase of $\mathrm{T}_{\text {off }}$

- TWR is inversely proportional to Ip and directly proportional to $\mathrm{T}_{\text {on }}$ and $\mathrm{T}_{\text {off }}$

- NSS electrode has higher effect on MRR than B2, while the effect of both electrodes for TWR was close to each other

- The minimum TWR was achieved at Ip $(6 \mathrm{~A}), \mathrm{T}_{\text {on }}(800 \mu \mathrm{s})$, and $\mathrm{T}_{\text {off }}(800 \mu \mathrm{s})$ and the maximum MRR achieved at Ip $(25 \mathrm{~A}), \mathrm{T}_{\text {on }}(800 \mu \mathrm{s})$, and $\mathrm{T}_{\text {off }}(200 \mu \mathrm{s})$. After applying GRA, the optimal parameters combination for MRR and TWR was determined as Ip (25A), $\mathrm{T}_{\text {on }}(800 \mu \mathrm{s}), \mathrm{T}_{\text {off }}(200 \mu \mathrm{s})$, and NSS electrode.

\section{REFERENCES}

Amorim, F.L. and Weingaertner, W.L., 2007. The behavior of graphite and copper electrodes on the finish die-sinking electrical discharge machining (EDM) of AISI P20 tool steel. Journal of the Brazilian Society of Mechanical Sciences and Engineering, 29(4), pp.366-371.

Antony, J., 2003. Design of Experiments for Engineers and Scientists. Elsevier Science and Technology Book, Amsterdam, Netherlands, pp.189-198.

Bhattacharyya, B., Gangopadhyay, S. and Sarkar, B.R., 2007. Modelling and analysis of EDMED job surface integrity. Journal of Materials Processing Technology, 189(1-3), pp.169-177.

Daniel, T., Liu, C., Mou, J. and Jahan, M.P., 2019. Micro-Wire-EDM. In: Microelectrical Discharge Machining Processes. Springer, Singapore, pp.67-92.

Dastagiri, M. and Kumar, A.H., 2014. Experimental investigation of EDM parameters on stainless steel and En41b. Procedia Engineering, 97(I), pp.1551-1564.

Doniavi, A., Eskandarza, M., Abdi, A. and Totonchi, A., 2008. Empirical modeling of EDM parameters using GRA. Asian Journal of Scientific Research, 1(5), pp.502-509.

Gopalakannan, S., Senthilvelan, T. and Ranganathan, S., 2013. Statistical optimization of EDM parameters on machining of aluminum Hybrid Metal Matrix composite by applying Taguchi based Grey analysis. Journal of Scientific and Industrial Research, 72(6), pp.358-365.

Guu, Y.H., 2005. AFM surface imaging of AISI D2 tool steel machined by the EDM process. Applied Surface Science, 242(3-4), pp.245-250.
Habib, S.S., 2009. Study of the parameters in electrical discharge machining through response surface methodology approach. Applied Mathematical Modelling, 33(12), pp.4397-4407.

Harpreet, S. and Amandeep, S., 2012. Effect of pulse on/pulse off time on machining of AISI D3 die steel using copper and brass electrode in EDM. International Journal of Engineering and Science, 1(9), pp.19-22.

Ho, K.H. and Newman, S.T., 2003. State of the art electrical discharge machining (EDM). International Journal of Machine Tools and Manufacture, 43(13), pp.1287-1300.

Jabbaripour, B., Sadeghi, M.H., Faridvand, S. and Shabgard, M.R., 2012. Investigating the effects of Edm parameters on surface integrity, MRR And TWR in machining of Ti-6al-4v. Machining Science and Technology, 16(3), pp.419-444.

Kalyon, A., Günay, M., Özyürek, D., 2018. Application of grey relational analysis based on Taguchi method for optimizing machining parameters in hard turning of high chrome cast iron. Advances in Manufacturing, 6(4), pp.419-429.

Kalyon, A., 2020. Optimization of machining parameters in sinking electrical discharge machine of caldie plastic mold tool steel. Sädhanā, 45(1), pp.1-13.

Krishnaiah, K. and Shahabudeen, P., 2012. Applied Design of Experiments and Taguchi Methods. PHI Learning Pvt. Ltd., New Delhi, pp.211-231.

Kumar, S., 2012. Copper-chromium alloy as a superior electrode material for electrical discharge machining of die steels. International Journal of Materials Engineering Innovation, 3, pp.316-329.

Lee, S.H. and Li, X.P., 2001. Study of the effect of machining parameters on the machining characteristics in electrical discharge machining of tungsten carbide. Journal of Materials Processing Technology, 115(3), pp.344-358.

Lin, J.L. and Lin, C.L., 2002. The use of the orthogonal array with grey relational analysis to optimize the electrical discharge machining process with multiple performance characteristics. International Journal of Machine Tools and Manufacture, 42(2), pp.237-244.

Muthuramalingam, T. and Mohan, B., 2015. A review on influence of electrical process parameters in EDM process. Archives of Civil and Mechanical Engineering, 15(1), pp.87-94.

Patil, K.K. and Jadhav, V.D., 2016. Study of machining parameters in EDM. International Journal for Research in Applied Science and Engineering Technology, 4(1), pp.72-78.

Ramabalan, J.J. and S., 2015. Die sinking edm process parameters: A review. International Journal of Engineering and Robotics Research, 4(1), pp.315-326.

Shyha, I. and Rudd, M., 2016. Electro-discharge machining of metal matrix composite materials. Advances in Materials and Processing Technologies, 2(2), pp.235-244.

Singh, K., 2018. Optimization of process parameters of powder mixed EDM for high carbon high chromium alloy steel (D2 steel) through GRA approach. Grey Systems: Theory and Application, 8(4), pp.388-398.

Singh, P.N., Raghukandan, K. and Pai, B., 2004. Optimization by grey relational analysis of EDM parameters on machining Al-10\%SiCP composites. Journal of Materials Processing Technology, 155, pp.1658-1661.

Venkatesh, B., Naveen, P., Maurya, B. and Priya, D.S., 2015. Experimental investigation of Edm using electrode materials copper, brass and chromium copper for alloy steels. International Journal of Advance Engineering and Research Development, 2(4), 1-12.

Yerui, F., Yongfeng, G. and Zongfeng, L., 2016. Experimental investigation of EDM parameters for TiC/Ni cermet machining. Procedia Cirp, 42, pp.18-22. 